\title{
Heptapeptide Isolated from Isochrysis zhanjiangensis Exhibited Anti-Photoaging Potential via MAPK/AP-1/MMP Pathway and Anti-Apoptosis in UVB-Irradiated HaCaT Cells
}

\author{
Zhaowan Zheng ${ }^{1,2,+}\left(\mathbb{D}\right.$, Zhenbang Xiao ${ }^{1,2,+}$, Yuan-Lin He ${ }^{1,2}$, Yanfei Tang ${ }^{1,2}$, Lefan Li ${ }^{1}$, Chunxia Zhou ${ }^{1,2}$, \\ Pengzhi Hong ${ }^{1,2}$, Hui Luo ${ }^{2,3}$ and Zhong-Ji Qian ${ }^{1,2, *}$ \\ 1 School of Chemistry and Environment, Shenzhen Institute of Guangdong Ocean University, \\ College of Food Science and Technology, Guangdong Ocean University, Zhanjiang 524088, China; \\ zzwzhengzhaowan@163.com (Z.Z.); xzhenbang@163.com (Z.X.); heylzzz@163.com (Y.-L.H.); \\ HYa0847@163.com (Y.T.); FLL@gdou.edu.cn (L.L.); chunxia.zhou@163.com (C.Z.); \\ hongpengzhigdou@163.com (P.H.) \\ 2 Southern Marine Science and Engineering Guangdong Laboratory, Zhanjiang 524025, China; \\ luohui@gdmu.edu.cn \\ 3 The Marine Biomedical Research Institute, Guangdong Medical University, Zhanjiang 524023, China \\ * Correspondence: zjqian@gdou.edu.cn; Tel.: +86-1860-759-6590 \\ + These authors contribute equally in this work.
}

Citation: Zheng, Z.; Xiao, Z.; He, Y.-L.; Tang, Y.; Li, L.; Zhou, C.; Hong, P.; Luo, H.; Qian, Z.-J. Heptapeptide Isolated from Isochrysis zhanjiangensis Exhibited Anti-Photoaging Potential via MAPK/AP-1/MMP Pathway and Anti-Apoptosis in UVB-Irradiated HaCaT Cells. Mar. Drugs 2021, 19, 626. https://doi.org/10.3390/ md19110626

Academic Editors: Immacolata Castellano, Elisabetta Damiani and Céline Couteau

Received: 6 October 2021

Accepted: 7 November 2021

Published: 9 November 2021

Publisher's Note: MDPI stays neutral with regard to jurisdictional claims in published maps and institutional affiliations.

Copyright: () 2021 by the authors. Licensee MDPI, Basel, Switzerland. This article is an open access article distributed under the terms and conditions of the Creative Commons Attribution (CC BY) license (https:// creativecommons.org/licenses/by/ $4.0 /)$.

\begin{abstract}
Marine microalgae can be used as sustainable protein sources in many fields with positive effects on human and animal health. DAPTMGY is a heptapeptide isolated from Isochrysis zhanjiangensis which is a microalga. In this study, we evaluated its anti-photoaging properties and mechanism of action in human immortalized keratinocytes cells (HaCaT). The results showed that DAPTMGY scavenged reactive oxygen species (ROS) and increase the level of endogenous antioxidants. In addition, through the exploration of its mechanism, it was determined that DAPIMGY exerted anti-photoaging effects. Specifically, the heptapeptide inhibits UVB-induced apoptosis through down-regulation of p53, caspase-8, caspase-3 and Bax and up-regulation of Bcl-2. Thus, DAPTMGY, isolated from I. zhanjiangensis, exhibits protective effects against UVB-induced damage.
\end{abstract}

Keywords: heptapeptide; photoaging; UVB; MMPs; apoptosis

\section{Introduction}

Skin aging is an irreversible natural physiological process related to free-radical formation in the skin [1]. Under the current conditions of the Earth's rotation, 280-3000 nm solar radiation reaches the Earth's surface, among which the 280-1600 nm wavelengths can be divided into ultraviolet (UV), visible light (VIS), and near infrared (IR) [2]. However, $\mathrm{UV}$ radiation is the most concerning due to its much higher photon energy than VIS and IR [3]. Of the UV radiation that reaches the Earth's surface, UVB $(280-320 \mathrm{~nm})$ is directly associated with photodamage and photoaging, as UVA $(320-400 \mathrm{~nm})$ confers approximately 1000-fold less photic damage than UVB [4]. Long-term exposure to UVB leads to skin wrinkling and collagen loss, which accelerates the premature aging of skin (so-called skin photoaging) [5,6]. The absorption of UVB can induce radical formation through photoionization. ROS are very reactive free-radical molecules involved in cellular damage and molecular signaling, and they play a crucial role in skin aging [4]. UVB-induced skin injury can lead to a large number of ROS-mediated signal transduction abnormalities, cell redox homeostasis imbalance, and excessive apoptosis. In addition, the UVB-mediated abnormal secretion of MMPs is also an important factor in the degradation of collagen. Whereas light damage can be self-repaired through epidermal thickening and the antioxidant system, this ability is limited in cases of severe damage [7,8]. Therefore, the use of various antioxidants to control UVB-induced damage is considered an important strategy. 
Microalgae are autotrophic unicellular microorganisms present within both aquatic and terrestrial ecosystems [9]. They are widely applied as carbon sequestration agents [10], food supplements [11], feed [12], and biofuel [13], as well as in the wastewater treatment field [14]. Moreover, microalgae have been considered as specific sources of peptides which contain potentially untapped physiological functions and exert a positive impact by binding to specific receptors, interacting with target cells, or inhibiting enzymes [11]. It was reported that the skin gelatin hydrolysate of pacific cod showed inhibitory activity toward MMP-1 expression in mouse skin fibroblasts exposed to UV radiation [15]. Recent studies demonstrated that microalgae-derived biopeptides display antioxidant, antimicrobial, antitumor, and antihypertensive activities. For example, a hexapeptide from Chlorella ellipsiodea (Leu-Asn-Gly-Asp-Val-Trp) was shown to have antioxidant activities via scavenging peroxyl and DPPH radicals [16]. Another peptide isolated from Tetraselmis suecica exhibited bactericidal effects against both Gram-negative and Gram-positive human pathogenic bacteria [17]. In addition, a peptide byproduct from Chlorella vulgaris processing (Val-GluCys-Tyr-Gly-Pro-Asn-Arg-Pro-Gln-Phe) was revealed to inhibit angiotensin I-converting enzyme (ACE) activity, thus exhibiting antihypertensive properties [18]. As presented above, the development and utilization of microalgae biopeptides is very promising.

There have been previous discoveries related to the activities of other peptides in Isochrysis zhanjiangensis. For example, peptides isolated from I. zhanjiangensis exhibited an antioxidant effect [19]. Chen et al. found that I. zhanjiangensis can inhibit angiotensin I-converting enzyme activity, thus exhibiting antihypertensive properties [20]. However, this research is neither extensive nor comprehensive; thus, there is a lack of accumulated results. In this study, we focused on whether a novel heptapeptide isolated from Isochrysis zhanjiangensis has anti-UVB-induced photoaging properties from the perspective of antioxidant and antiapoptotic activity and the inhibition of MMP secretion. As a result, the utilization value of Isochrysis zhanjiangensis can be improved, and the mechanistic activity of its isolated polypeptides can be supplemented through protein hydrolysis.

\section{Results}

\subsection{UVB Stimulation and Effect of DAPTMGY on HaCaT Cell Viability}

As shown in Figure 1a, after coculture with DAPTMGY, the viability of HaCaT cells revealed no significant change, demonstrating that the DAPTMGY concentration range of $1-200 \mu \mathrm{M}$ is safe. Thus, $0,20,50$, and $100 \mu \mathrm{M}$ concentrations of DAPTMGY were used in the subsequent experiments. Cells were cultured with different DAPTMGY concentrations for $24 \mathrm{~h}$ (Figure $1 \mathrm{~b}$ ). The data indicated that DAPTMGY (50 and $100 \mu \mathrm{M})$ can effectively enhance cell viability in the presence of UVB.

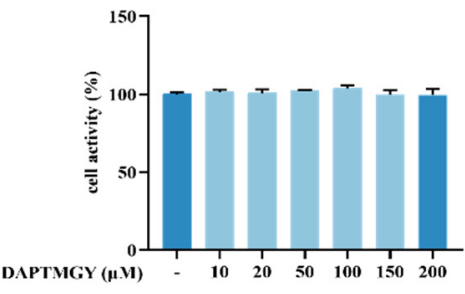

(a)

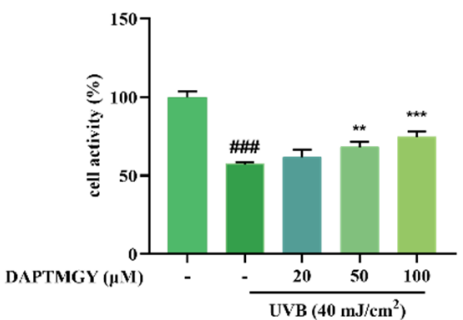

(b)

Figure 1. Effect of DAPTMGY on cell viability of HaCaT cells. (a) the viability of various doses of DAPTMGY $(0,10,20,50,100,150$, and $200 \mu \mathrm{M})$ on HaCaT cells; (b) protective effects of DAPTMGY $(0$, $20,50$ and $100 \mu \mathrm{M})$ on UVB -induced $\left(40 \mathrm{~mJ} / \mathrm{cm}^{2}\right) \mathrm{HaCaT}$ cell injury. Data are shown as mean \pm S.D $(n=3)$. (\#\#) $p<0.001$, as compared to the blank group (untreated cells). ${ }^{* *} p<0.01$ and ${ }^{* * *} p<0.001$, respectively, as compared to the control group. 


\subsection{Reducing Effect of DAPTMGY on Intracellularly Overexpressed ROS}

Intracellular ROS changes were detected using the $2^{\prime}, 7^{\prime}$-dischlorodihydrofluorescein diacetate (DCFH-DA) fluorescent probe. Compared to the blank group, UVB irradiation led to significant fluorescence in HaCaT cells. However, as the concentration of DAPTMGY increased, the fluorescence signal gradually decreased (Figure 2a). Mean optical density analysis revealed that a relatively high concentration of heptapeptide could significantly reduce the ROS content $(p<0.01)$.

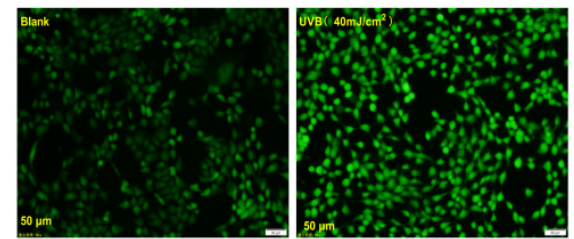

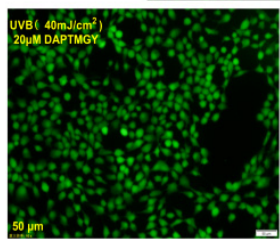

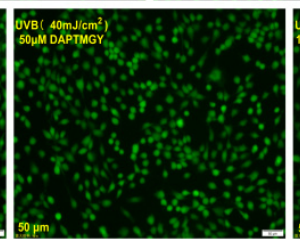

(a)

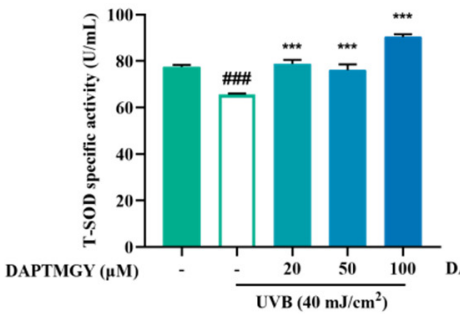

(c)

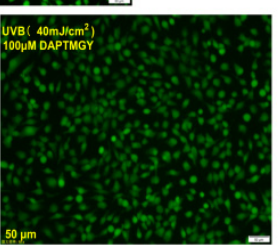

Der

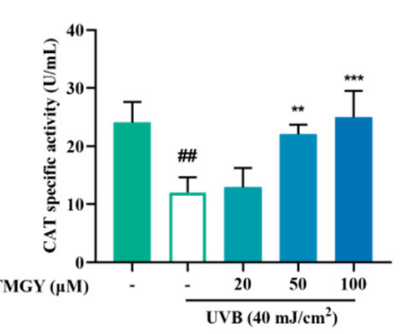

(d)

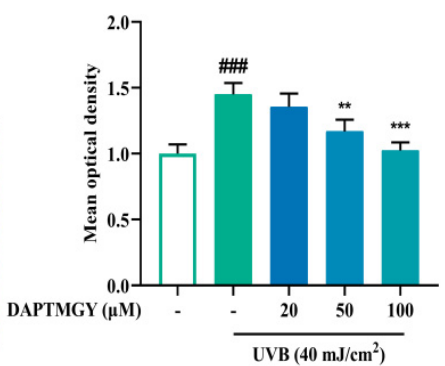

(b)

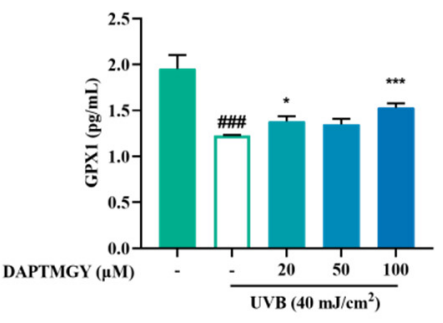

(e)

Figure 2. Effect of DAPTMGY on intercellular ROS generation and on the contents of Total superoxide dismutase (T-SOD), catalase (CAT) and glutathione peroxidase 1 (GPX1) in UVB-stimulated (40 mJ/ $\left.\mathrm{cm}^{2}\right) \mathrm{HaCaT}$ cells. Cells were cultured with DAPTMGY $(20,50$, and $100 \mu \mathrm{M})$ for $2 \mathrm{~h}$ and then cultured for another $24 \mathrm{~h}$ after UVB irradiation. (a) Intercellular ROS production was measured in intact HaCaT cells using DCFH-DA, and photos were captured under fluorescence inverted microscopy. (b) The relative DCF fluorescence intensity analysis was conducted using Image J (fluorescence experiments were performed four times; $n=3$ per group). (c-e) The levels of T-SOD, CAT, and GPX1 were measured using biochemical assay kits and ELISA kits. Results are shown as the mean $\pm \operatorname{SD}(n=3) .{ }^{\# \#} p<0.01$ and ${ }^{\# \#} p<0.001$ compared to the blank group (untreated cells); ${ }^{*} p<0.05,{ }^{* *} p<0.01$, and ${ }^{* * *} p<0.001$ compared to the control group.

\subsection{Regulatory Effect on Antioxidant Enzyme Activities}

As shown in Figure $2 c-e$, compared to the UVB-stimulated group, the activities of T-SOD $(p<0.001)$, CAT $(p<0.01)$, and GPX1 $(p<0.05)$ were obviously enhanced after treatment with DAPTMGY. The results indicated that DAPTMGY can enhance the activities of endogenous antioxidant enzymes such as SOD, CAT, and GPX1.

\subsection{Detection of Related Apoptosis Proteins}

The expression of signaling pathways related to apoptosis, namely, Bax, Bcl-2, caspase3, and caspase-8, was observed in UVB-exposed cells cultured with DAPTMGY (Figure 3). A significant upregulation of proapoptotic genes Bax, caspase-3, and caspase-8 was observed in the UVB + DAPTMGY group compared to the control group. Furthermore, an associated significant increase in antiapoptotic gene Bcl-2 was observed. Apoptosis depends on the activation of receptors in the mitochondrial-dependent death pathway, while 
the process is also affected by many other signaling pathways, such as p53 [21]. Therefore, the effect of DAPTMGY on p53 was evaluated (Figure 3). Western blot analysis showed that the level of p53 in the control group was significantly upregulated, whereas it was reduced after DAPTMGY treatment (Figure 3c). As shown in Figure 4a, after UVB exposure, p53 was significantly transferred into the nucleus. Subsequently, $100 \mu \mathrm{M}$ DAPTMGY treatment effectively suppressed p53 nuclear translocation in $\mathrm{HaCaT}$ cells. As shown in Figure 3f, the comet tail of DAPTMGY at $100 \mu \mathrm{M}$ concentration was shorter than that of the control group, indicating that a high concentration of DAPTMGY reduced the DNA damage induced by UVB.

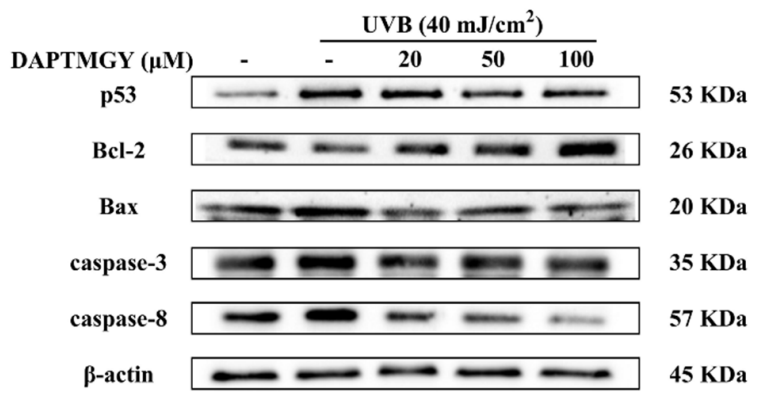

(a)

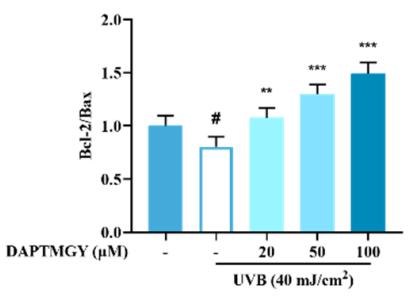

(c)

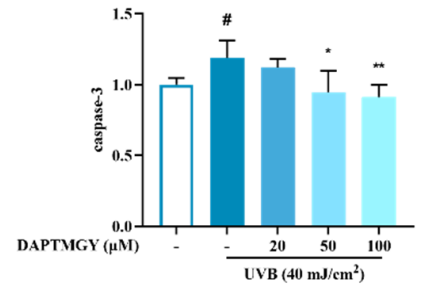

(d)

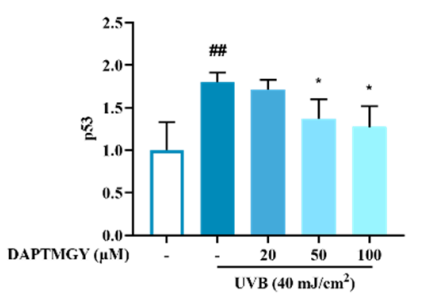

(b)

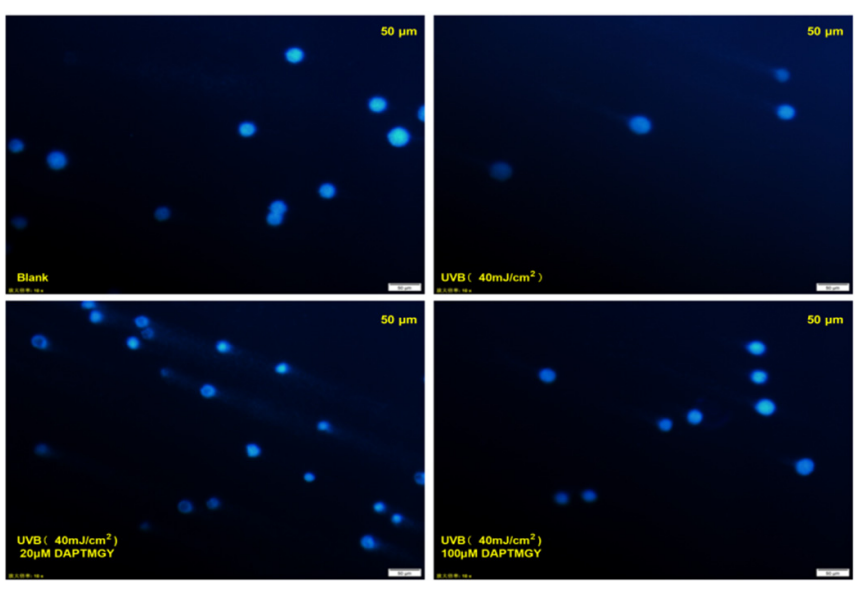

(f)

Figure 3. Cont. 


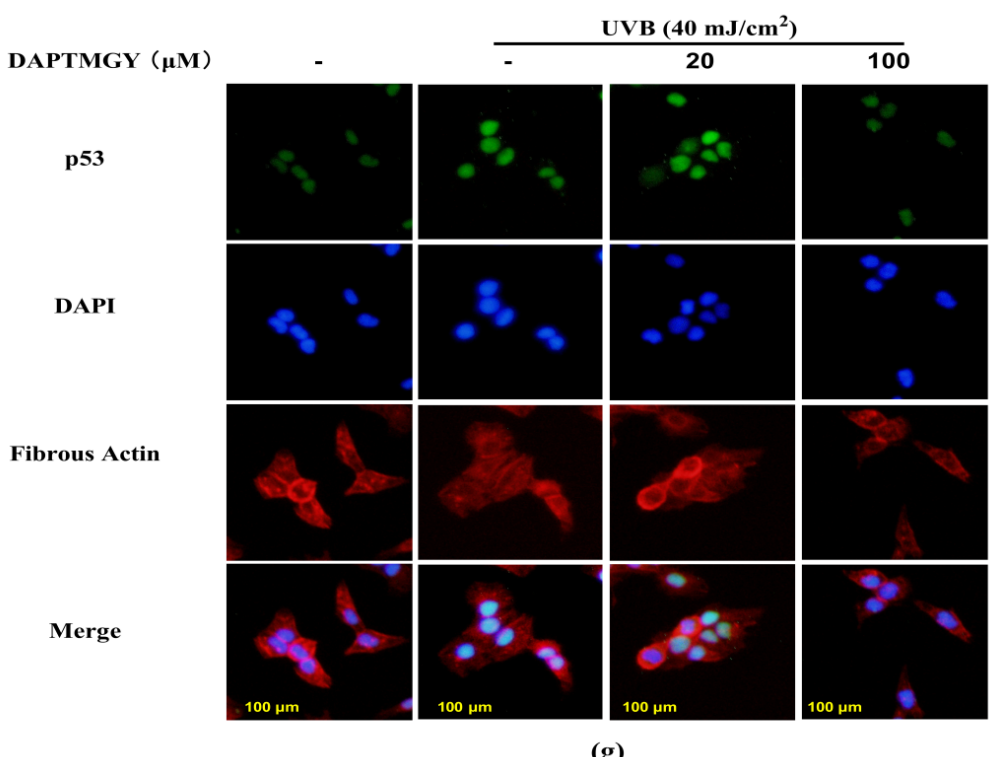

Figure 3. The influence of DAPTMGY on the levels of related apoptosis proteins in UVB-stimulated HaCaT cells. (a) Western blotting bands of p53, Bcl-2, Bax, caspase-3 and caspase-8. (b,d,e) The proteins expression of p53, caspase-3 and caspase-8, respectively. (c) The ratios of Bcl-2/Bax. (f) HaCaT cells stained with DAPI were observed using an inverted fluorescence microscope. (g) Nuclear translocation of p53 was observed by immunofluorescence through an overlay of green p53 staining, blue DAPI staining and Actin red. Data are shown as mean \pm S.D $(n=3)$. (\#, \#\# and \#\#\#) $p<0.05$, $p<0.01$ and $p<0.001$, as compared to the blank group (untreated cells). ${ }^{*} p<0.05,{ }^{* *} p<0.01$ and *** $p<0.001$, respectively, as compared to the control group. $\beta$-actin was used as an internal control.

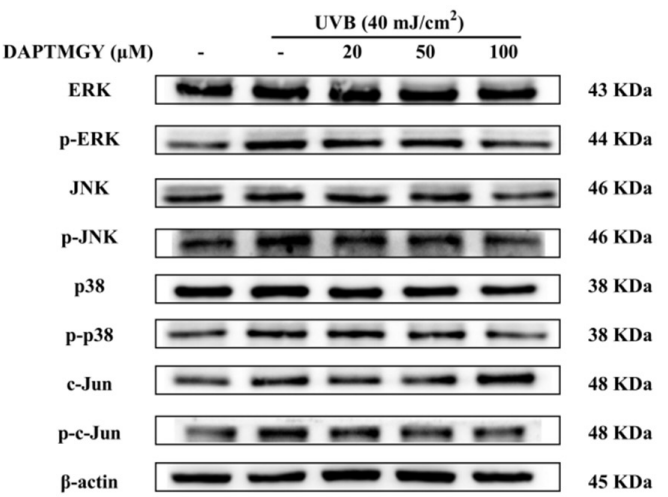

(a)

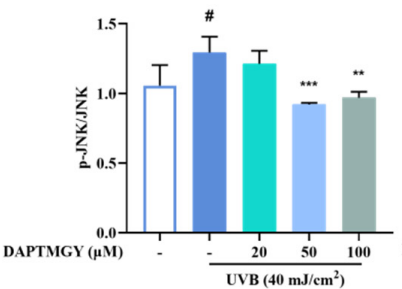

(c)

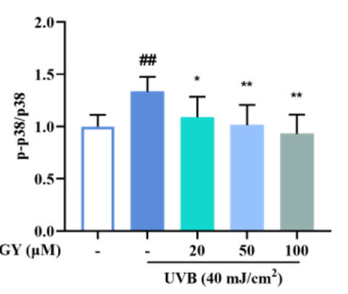

(d)

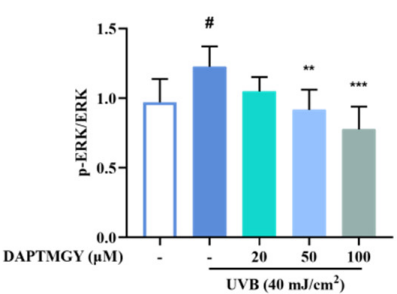

(b)

Figure 4. DAPTMGY blocked phosphorylation of ERK, p-38 and c-Jun in UVB-stimulated HaCaT cells. (a) Western blotting bands of MAPK pathway and AP-1. (b) The ratios of p-ERK/ERK, (c) The ratios of $\mathrm{p}-\mathrm{JNK} / \mathrm{JNK}$, (d) The ratios of p-p38/p38 and (e) The ratios of p-c-Jun/c-Jun are calculated respectively. Data are shown as mean \pm S.D $(n=3)$. (\# and \#\#) $p<0.05$ and $p<0.01$, as compared to the blank group (untreated cells). ${ }^{*} p<0.05,{ }^{* *} p<0.01$ and ${ }^{* * *} p<0.001$, respectively, as compared to the control group. $\beta$-actin functioned as the internal control. 


\subsection{DAPTMGY Regulates UVB-Induced MAPKs and AP-1 Activation}

UVB irradiation upregulated the expression of p-c-Jun compared with the control group. However, treatment with DAPTMGY decreased the expression of p-c-Jun (Figure 4e). Compared with the blank group, the phosphorylation levels of ERK, JNK, and p38 were increased after UVB irradiation (Figure 4). Treatment with $20 \mu \mathrm{M}$ DAPTMGY had no impact on the phosphorylated levels of ERK and JNK. However, the p-p38/p38 ratio was significantly decreased. At the concentration of $100 \mu \mathrm{M}$, it can be seen that the phosphorylation level of MAPK was significantly downregulated (Figure $4 b-d$ ), indicating that DAPTMGY can inhibit the signal pathways (MAPK and AP-1) related to photoaging.

\subsection{Influence of DAPTMGY on NF- $\kappa B$ Signaling Pathway}

Compared with the blank group, the phosphorylation levels of p65 and IкB were significantly increased after UVB stimulation. Contrarily, the p-p65/p65 and p-IкB/IкB ratios exhibited a dose-dependent decrease (Figure $5 b, c$ ), whereas the p-p50/p50 ratio showed no significant change (Figure 5d), indicating that DAPTMGY inhibited the NF- $\mathrm{kB}$ signaling pathway.

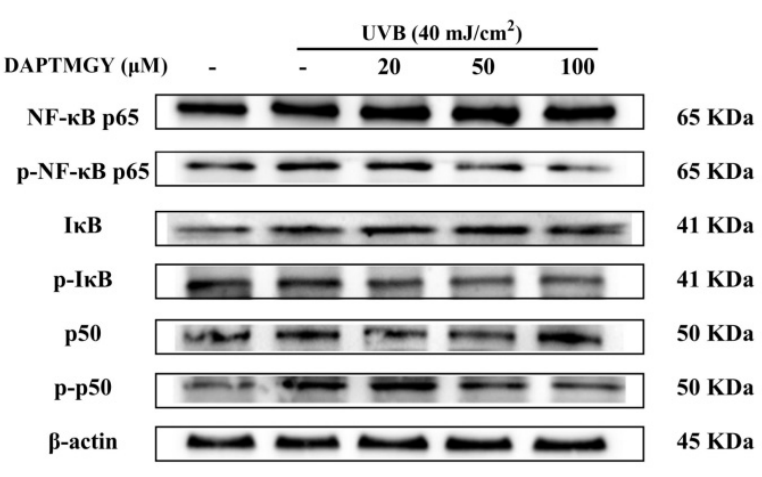

(a)

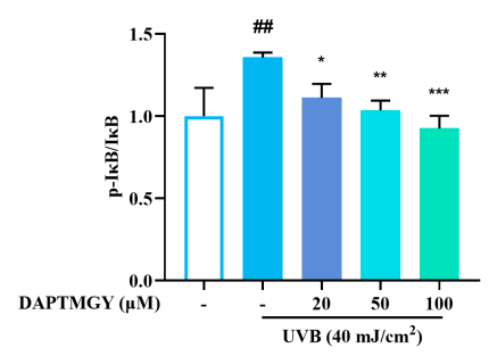

(c)

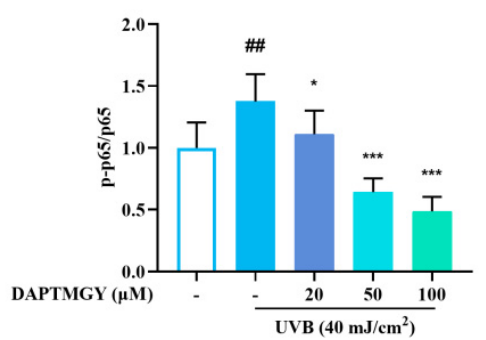

(b)

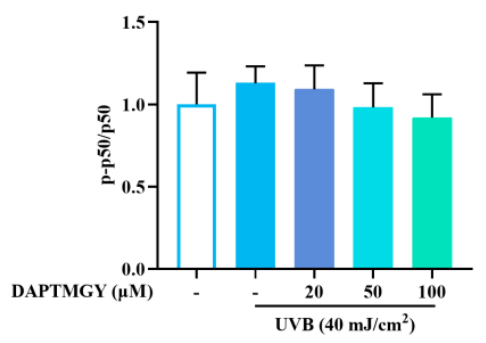

(d)

Figure 5. DAPTMGY suppressed the UVB-stimulated NF- $\kappa B$ signal pathway in HaCaT. (a) Western blotting bands of expression of NF- $\mathrm{B}$ pathway. (b-d) The ratios of $\mathrm{p}-\mathrm{NF}-\kappa \mathrm{B}$ p65/NF- $\mathrm{kB}$ p65, $\mathrm{p}-$ $\mathrm{I} \kappa \mathrm{B} / \mathrm{I} \kappa \mathrm{B}$ and p-p50/p50 are calculated respectively. $\beta$-actin functioned as the control and all of the experiments were performed in at least triplicate. Data are shown as mean $\pm \operatorname{S.D}(n=3)$. (\#\#) $p<0.01$, as compared to the blank group (untreated cells). ${ }^{*} p<0.05,{ }^{* *} p<0.01$ and ${ }^{* * *} p<0.001$, respectively, as compared to the control group. $\beta$-actin functioned as the internal control.

\subsection{Expression Levels of MMP and Procollagen I Concentration}

UVB irradiation resulted in a significant increase in the secretions of MMP-1 and MMP3 and a significant decrease in procollagen I compared with the control group. However, culture with 20-100 $\mu \mathrm{M}$ DAPTMGY decreased the MMP-1 and MMP-3 secretions and increased the content of procollagen I in HaCaT cells (Figure 6), evidencing the antiphotoaging activity of DAPTMGY. 


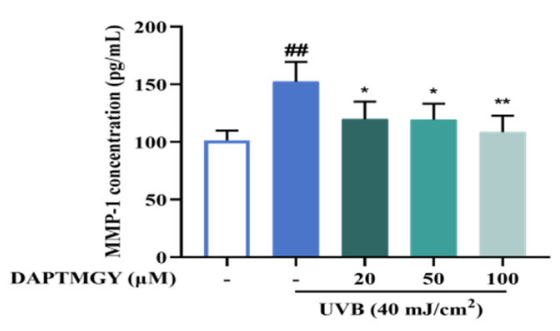

(a)

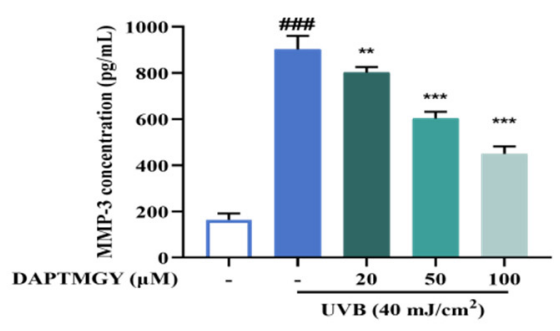

(b)

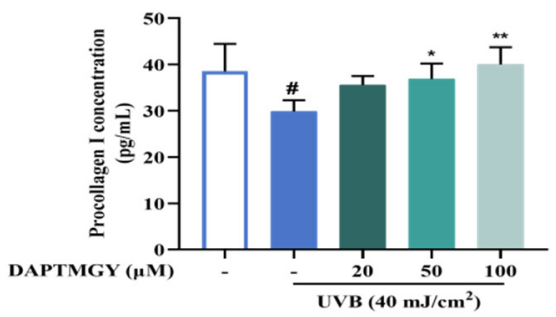

(c)

Figure 6. DAPTMGY suppresses MMP-1 and MMP-3 secretion and increase procollagen I. (a) The secretion in condition media of MMP-1, (b) The secretion in condition media of MMP-3, and (c) The secretion in condition media of procollagen I was assessed by ELISA kit. Data are shown as mean \pm S.D $(n=3)$. (\#, \#\# and \#\#\#) $p<0.005, p<0.01$ and $p<0.001$, as compared to the blank group (untreated cells). ${ }^{*} p<0.005,{ }^{* *} p<0.01$ and ${ }^{* *} p<0.001$, respectively, as compared to the control group.

\subsection{Molecular Docking Analysis of MMP-1 and MMP-3 with DAPTMGY}

The docking simulation results revealed multiple interactions between DAPTMGY and MMP-1/MMP-3. These interactions were hydrophobic in nature, as clearly shown in Figure 7 and Table 1. The optimal CDOCKER interaction energy between DAPTMGY and MMP-1 and MMP-3 was -84.90 and $-71.92 \mathrm{kcal} / \mathrm{mol}$, respectively. DAPTMGY formed nine hydrogen bonds with MMP-1, including amino-acid residues Pro173, Asn180, Ala182 (two bonds), Leu235, Tyr237 (two bonds), Thr241, and Gln247. On the other hand, it formed five hydrogen bonds with MMP-3, including amino-acid residues Ala165, Thr215, Tyr220, His224, and Asp228. In addition, two pi-anion bonds and four pi-alkyl bonds were formed with MMP-1, while one pi-sulfur bond and six pi-alkyl bonds were formed with MMP-3.

Table 1. Results of DAPTMGY docking with MMP-1 and MMP-3, respectively.

\begin{tabular}{|c|c|c|c|c|}
\hline DAPTMGY & $\begin{array}{l}\text { Interaction Energy } \\
(-\mathrm{kcal} / \mathrm{mol})\end{array}$ & $\begin{array}{c}\text { Hydrogen Bond } \\
\text { Number }\end{array}$ & Interaction Atoms & Distance (Å) \\
\hline \multirow{7}{*}{ MMP-1(966C) } & \multirow{7}{*}{84.90} & \multirow{7}{*}{9} & Pro173 & 1.74 \\
\hline & & & Asn180 & 2.09 \\
\hline & & & Ala182 & 2.05 \\
\hline & & & Leu235 & 3.09 \\
\hline & & & Tyr237 & 2.45 \\
\hline & & & Thr241 & 2.31 \\
\hline & & & $G \ln 247$ & 1.96 \\
\hline \multirow{5}{*}{ MMP-3(2JT6) } & \multirow{5}{*}{71.92} & \multirow{5}{*}{5} & Ala165 & 1.89 \\
\hline & & & Thr215 & 2.28 \\
\hline & & & Tyr220 & 2.86 \\
\hline & & & His224 & 3.08 \\
\hline & & & Asp228 & 1.85 \\
\hline
\end{tabular}




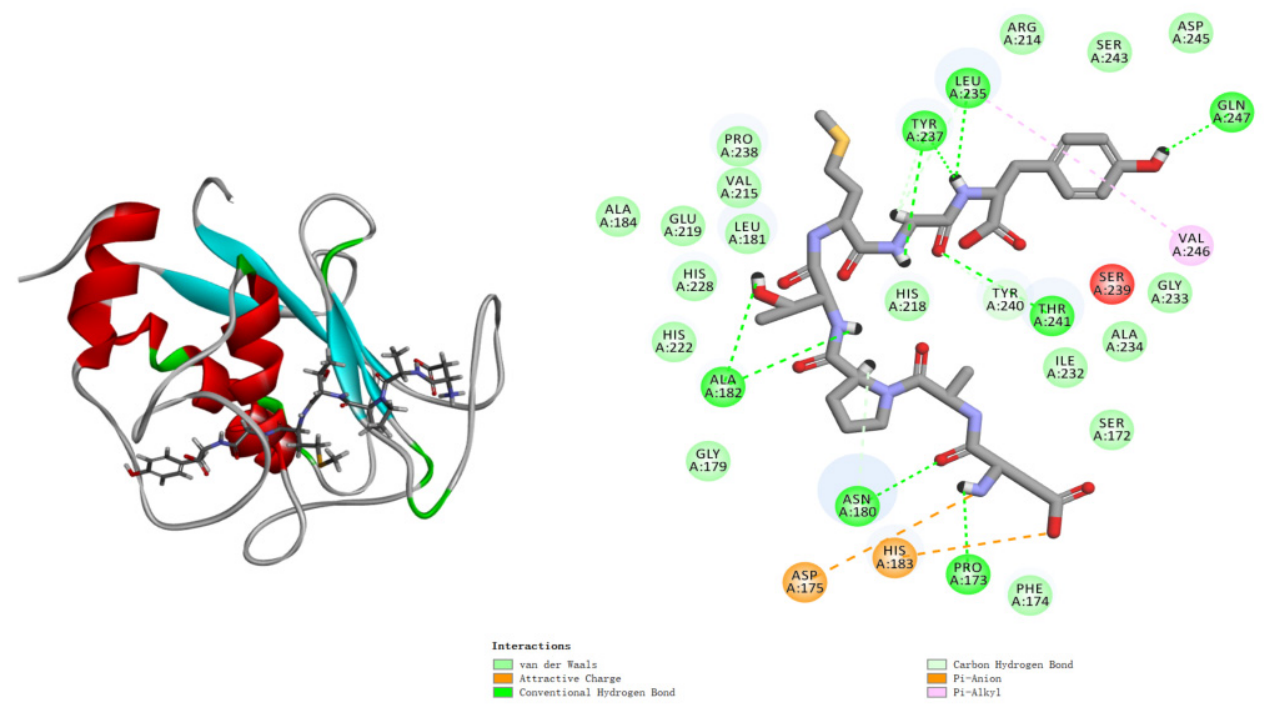

(a)
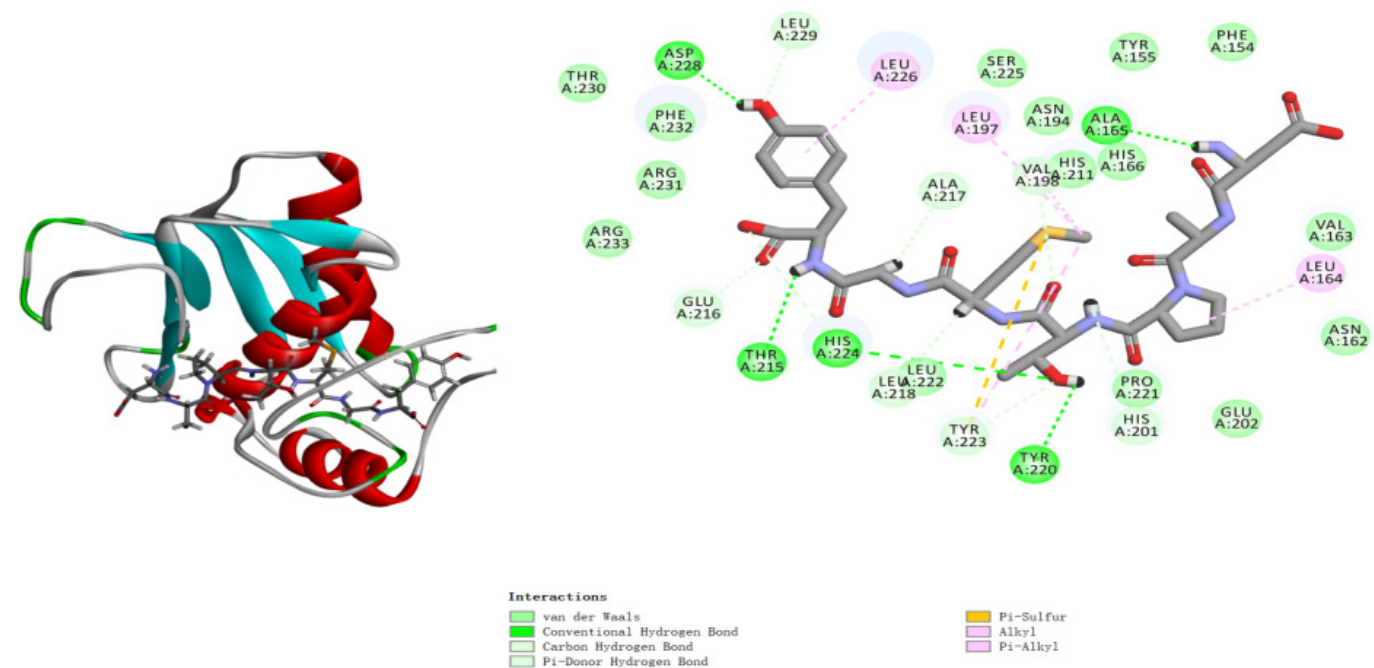

(b)

Figure 7. DAPTMGY interacted with MMP-1 (a) and MMP-3 (b). The optimal 3D poses structure and two-dimensional diagram of DAPTMGY and MMP-1 and MMP-3. Sticks stand for DAPTMGY and dotted lines is represent bond formation.

\section{Discussion}

Active peptides often show good biological activity at low doses, which is an important feature of bioactive peptides [22]. The results of this study showed that DAPTMGY exhibited better protection against phototoxicity, as well as biocompatibility, in the concentration range of $20-100 \mu \mathrm{M}$. It can be seen that heptapeptide DAPTMGY isolated from Isochrysis zhanjiangensis has good potential as an anti-photoaging agent. The antiphotoaging protective mechanism was further explored with respect to oxidative stress and cell apoptosis.

Skin exposure to UVB activates oxidative stress of the epidermis [23]. On the one hand, under oxidative stress, excess ROS could overwhelm endogenous antioxidants (T-SOD, CAT, GPX1, etc.), leading to irreversible accumulation in cells [24,25], thus damaging the 
mitochondrial structure, collapsing the mitochondrial membrane potential, and initiating key apoptotic events. In this research, the generation of ROS was enhanced by UVB stimulation. Interestingly, DAPTMGY treatment could reduce ROS production, as well as increase the intracellular activities of T-SOD, CAT, and GPX1, thereby contributing to improved redox balance in UVB-damaged cells. To deduce its source of antioxidant activity, the composition of DAPTMGY was analyzed. Asp at the N-terminus of the heptapeptide can prevent the oxidation of unsaturated fatty acids [26] and is often used as a stabilizer of vitamin $\mathrm{E}$ in cosmetics and medicines. In addition, Asp-Ala may be a key antioxidant amino-acid fragment. The peptide Ala-Asp-Ala-Phe with the highest antioxidant activity was identified for the first time from walnut protein hydrolysate [27]. Byproducts from the hydrolysis of tuna (Trp-Gly-Asp-Ala-Gly-Gly-Try-Try) exhibited good antioxidant activity [28], with the phenolic hydroxyl group of Tyr at the C-terminus being an excellent hydrogen donor [29]. Moreover, the presence of the sulfur-containing amino acid Met strengthens the antioxidant properties of peptides [30]. It has been reported that methionine is widely applied in the medical care, animal breeding, and food additive industries [31]. The existence of these amino acids likely contributed to the good antioxidant capacity of DAPTMGY.

On the other hand, as a critical signal intermediate, ROS activates the expression of apoptotic genes and leads to apoptosis [32]. Controlled by Bcl-2 family proteins, death receptors, caspases, etc., cell apoptosis is primarily divided into exogenous and endogenous pathways [33]. In the exogenous pathway, death receptors are clustered and internalized in keratinocytes after UVB irradiation, resulting in caspase-8 initiation. Subsequently, the apoptosis signal is amplified by executioner caspases- 3 in the cells. The results of this study are consistent with this mechanism. The intrinsic pathway involved in UVB-induced apoptosis results from DNA damage and further generates intracellular ROS [34]. This process is mainly orchestrated by Bcl-2 family members, which comprise antiapoptotic and proapoptotic proteins. It is worth noting that the ratio of anti- and proapoptotic Bcl-2 family proteins (Bcl-2/Bax), which modulate the mitochondrial pathway, appears to determine the sensitivity to apoptotic stimuli, as opposed to the expression of a single protein [35]. ROS lead to DNA damage in cells [36], resulting in p53 accumulation in the nucleus, which directly regulates the expression of proapoptotic gene Bax. p53 also accumulates in the cytoplasm, where it directly binds to $\mathrm{Bcl}-2$ and interacts with the mitochondrial-mediated pathway to regulate apoptosis [37]. Furthermore, Bcl-2 can also activate Bax under signals inducing apoptosis, whereby Bax is oligomerized and inserted into the outer mitochondrial membrane [38]. Subsequently, mitochondria leakage of cytochrome $C$ activates caspase3 and induces apoptosis [39]. In our study, DAPTMGY was demonstrated to decrease the expression of p53 in the nucleus and concomitantly enhance the expression of Bcl-2 proteins, along with a decrease in Bax protein expression in HaCaT cells. Therefore, a shift in the Bax/Bcl-2 ratios prevented mitochondrial-mediated apoptosis. The results show that DAPTMGY significantly inhibited expression of the caspase cascade (caspases-3 and -8), resulting in the inhibition of apoptosis. p53 is not only a transcriptional factor, but also a major sensor of DNA damage, thus acting as an important regulator of DNA repair [40]. Normal cells irreversibly exit the cell cycle (senescence) upon telomere attrition and DNA damage [41]. In UVB-irradiated cells, DNA damage activates p53 and leads to cell-cycle arrest, leading to rapid aging and excessive apoptosis [42]. Moreover, UVB exposure leads to tissue damage through apoptosis [43]. Therefore, the upregulation of p53 as a cell-cycle inhibitor can induce apoptosis in response to DNA damage [44]. Moreover, DAPTMGY downregulated the expression level of p53 in the nucleus, ultimately inhibiting cell apoptosis and preventing photodamage. Therefore, our research proves that DAPTMGY can inhibit apoptosis through the intrinsic and extrinsic pathways. In addition, the overexpression of MMPs is the key to destroying the extracellular matrix (ECM) and leading to a loss of skin elasticity and a reduction in collagen. Oxidative stress can disrupt the balance between the accumulation and degradation of ECM components that support skin tissue structure and function; hence, MAPKs (ERK, JNK, and P38) and NF-kB (p50 
and p65) that regulate oxidative stress [45] can regulate the gene expression of MMP-1 and MMP-3 in photoaging [46]. The UV-induced excess of intracellular ROS activates MAPKs and NF- $\kappa B$, culminating in the transcriptional regulation of MMPs, especially MMP-1 and MMP-3. Additionally, the transcription factor AP-1 controls the expression of MMPs through the MAPK signaling pathway and inhibits transforming growth factor $\beta$ signaling, caused a decrease in procollagen synthesis $[47,48]$. This leads to the degradation of collagen and elastin, which is an important sign of photoaging. According to the Western blot results, the levels of phosphorylated ERK, JNK, and p38 decreased after DAPTMGY treatment. MAPKs were activated, thus triggering NF- $\mathrm{B}$ activation. In this study, the ratios

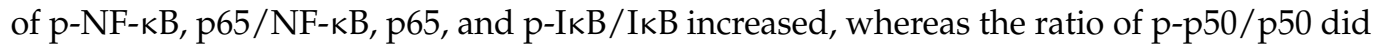
not change significantly. ELISA revealed that UVB irradiation leads to the overexpression of MMPs; however, DAPTMGY can protect against collagen degradation to some extent (Figure 5a,b).

Molecular docking studies have been helpful in earlier research to explore proteinligand interactions $[49,50]$. In order to explore the interaction between DAPTMGY and MMPs, the active-site residues of MMP-1 and MMP-3 models were kept flexible and then docked with the DAPTMGY ligand to explore possible pathways for the inactivation of these proteins. The structures of MMPs are similar, with the main differences occurring in their hydrophobic domains (S1' pocket), whereby many inhibitors typically occupy the S1' pocket [51]. MMPs and DAPTMGY formed many interactions (pi-anion, pi-alkyl, pi-sulfur, etc.), with hydrogen bonding being the predominant contributor [52,53]. Our results show that DAPTMGY formed nine hydrogen bonds with MMP-1 and five hydrogen bonds with MMP-3 residues (Table 1), including with the polar atoms of amino-acid residue Thr241 in the S1' pocket and Asn180 in the S3' pocket. Moreover, the hydroxyl groups of DAPTMGY formed shorter hydrogen bonds with Gln247 and ionic interactions with the polar nitrogen atom of Ala182. Therefore, this study suggests that the inhibition of MMP-3 by DAPTMGY may be mediated by hydrogen bonding with Ala165 in the S1 pocket. In addition, DAPTMGY could also interact with the MMP-1 active site. The inactivation of these MMPs would lead to a reduction in their expression.

DAPTMGY holds promising potential as an anti-photoaging drug substitute for UVB-induced damage with antiapoptotic effects; however, subsequent in vivo animal experiments, evaluations in other skin cells, and pharmacokinetic analyses are required to further confirm its effects.

\section{Materials and Methods}

\subsection{Chemicals and Materials}

Dulbecco's modified eagle's medium (DMEM), fetal bovine serum (FBS), trypsinEDTA $(0.25 \%)$ and penicillin/streptomycin were purchased from Gibco (New York, NY, USA). Cell Counting Kit was produced by ZETA LIFE Inc. (Menlo Park, CA, USA). 4',6diamidino-2-phenylindole (DAPI), 2,7-dichlorodihydroflfluorescein diacetate (DCFH-DA) was obtained from Sigma-Aldrich (St. Louis, MO, USA). ELISA kits of MMP-1 (E-ELH6073), MMP-3 (E-EL-H1446c), procollagen I (E-EL-H0181c) and Glutathione peroxidase 1 (GPX1, E-EL-H5410c) were purchased from Elabscience Biotechnology Co., Ltd. (Wuhan, China). Total superoxide dismutase (T-SOD, E-BC-K019-M) and Catalase (CAT, E-BCK031-M) were purchased from Elabscience Biotechnology Co., Ltd. (Wuhan, China). P-c-Jun (9261), c-Jun (9165), Bcl-2 (3498), Bax (2772) and c-3 (14,220) were provided by Cell Signaling Technology (CST, MA, USA). p65 (sc8008), p-p65 (sc-136548), p50 (sc-8414), p-p50 (sc-271908), IкB- $\alpha$ (sc-1643), p-IкB- $\alpha$ (sc-8404), ERK (sc-94), p-ERK (sc-81492), JNK (sc-7345), p-JNK (sc-6254), p38 (sc-535), p-p38 (sc-166182), p53 (sc-126), c-8 (sc-5263), $\beta$-actin $(47,778)$, antibodies (goat anti-rabbit IgG-HRP, sc-2004; goat anti-mouse IgG-HRP, sc-2005) were provided by Santa Cruz Biotechnology Inc. (Santa Cruz, CA, USA). All other drugs and solvents used are analytical grade. 


\subsection{Amino Acid Sequence Identification of DAPTMGY}

The novel peptide was isolated from Isochrysis zhanjiangensis hydrolysate obtained in our previous study [19]. The molecular mass of the peptide was analyzed, and the amino-acid sequence was determined using a Synchropak RPP-100 analytical column $(4.6 \times 250 \mathrm{~mm})$ and a Q-TOF mass spectrometer coupled with an electrospray ionization (ESI) source (Micromass, Altrincham, UK). Its molecular mass was evaluated by mass spectroscopy in the double-charged state $[\mathrm{M}+2 \mathrm{H}]^{2+}$ (data not shown). The amino-acid sequence was plotted using pepdraw (http:/ / www.tulane.edu/ biochem/WW/PepDraw/, accessed on 5 October 2021) (Figure 8).

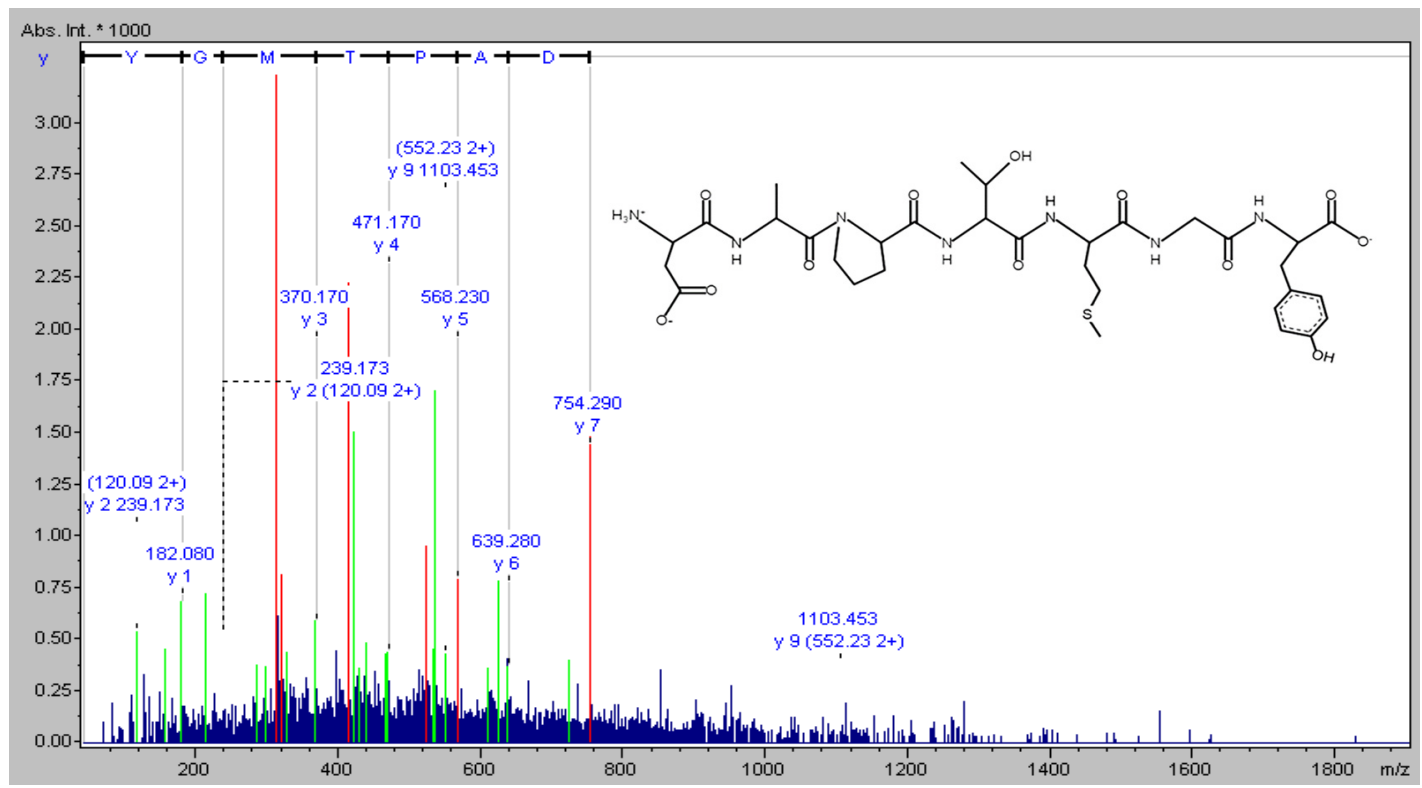

Figure 8. The amino acid sequence of DAPTMGY.

\subsection{Cell Culture}

Human immortalized keratinocytes (HaCaT) cells were bought from Shanghai IBS cell resource center. HaCaT cells were incubated $\left(37^{\circ} \mathrm{C}, 5 \% \mathrm{CO}_{2}\right)$ in DMEM $(12 \% \mathrm{FBS}$ and $1 \%$ penicillin/streptomycin).

\subsection{UVB Irradiation and DAPTMGY Treatment}

Cells grown to a suitable density were treated with different concentrations of DAPTMGY (20, 50, and $100 \mu \mathrm{M})$ for $2 \mathrm{~h}$, washed with phosphate-buffered saline (PBS), and exposed to UVB light using a Philips PL-S 9W/01 source (peak emission at $311 \mathrm{~nm}$; Royal Dutch Philips Electronics Ltd., Amsterdam, Holland). In this study, $40 \mathrm{~mJ} / \mathrm{cm}^{2}$ was selected as the radiation dose. The blank group was treated with serum-free medium and no UVB irradiation, whereas the control group was treated with UVB irradiation without DAPTMGY; the remaining groups were treated with different concentrations of DAPTMGY. The cells and supernatants were used for subsequent experiments after $24 \mathrm{~h}$.

\subsection{Determination of Cytotoxicity}

Cytotoxicity was assessed using the CCK-8 assay. Cells were seeded at $1 \times 10^{4}$ cells/well in 96-well plates, exposed to UVB irradiation, and treated with different concentrations of DAPTMGY. Following $24 \mathrm{~h}$ incubation, $10 \mu \mathrm{L}$ of CCK was added, and the reaction occurred at $37{ }^{\circ} \mathrm{C}$. Next, the absorbance of each well was detected after $1 \mathrm{~h}$ at $450 \mathrm{~nm}$ using a microplate reader (BioTek, Winooski, VT, USA). 


\subsection{Content of Intracellular ROS}

After treatment with different concentrations of DAPTMGY and irradiation with $40 \mathrm{~mJ} / \mathrm{cm}^{2} \mathrm{UVB}, \mathrm{HaCaT}$ Cells were processed using a DCFH-DA fluorescent probe, kept away from light for $30 \mathrm{~min}$ at $37^{\circ} \mathrm{C}$, and then washed with PBS three times. Treated cells were observed using an inverted fluorescence microscope (Olympus, Tokyo, Japan).

\subsection{Western Blotting}

An equal amount of protein was subjected to SDS-PAGE before transferring to PVDF membranes. Subsequently, the membranes were blocked by $7 \%$ defatted milk for $2 \mathrm{~h}$ before adding primary antibodies overnight at $4{ }^{\circ} \mathrm{C}$. Then, they were washed three times with TBST before binding to secondary antibodies for $2 \mathrm{~h}$. Finally, the results were evaluated by enhanced chemiluminescence.

\subsection{Analysis of Intracellular T-SOD, CAT and GPX1}

Samples of different concentrations and cells irradiated by UV were scraped and placed in a $1.5 \mathrm{~mL}$ centrifuge tube. Then, the supernatant was extracted after centrifugation at 13,000 rpm for $10 \mathrm{~min}$ at $4{ }^{\circ} \mathrm{C}$. The supernatant underwent three freeze-thaw cycles. The activities of T-SOD, CAT, and GPX1 were determined using biochemical assay kits according to the manufacturer's recommended protocol.

\subsection{Enzyme-Linked Immunosorbent Assay of MMP-1, MMP-3 and Type I Procollagen}

The secretions of MMP-1, MMP-3, and type I procollagen in cellular supernatants were detected by commercially available ELISA kits (Elabscience, Wuhan, China). Cells irradiated by UVB were treated with different concentrations of DAPTMGY $(0,20,50$, and $100 \mu \mathrm{M})$ for $24 \mathrm{~h}$. Conditional medium or a solution containing cell lysates was harvested in tubes and centrifuged $\left(12,000 \mathrm{rpm}, 4^{\circ} \mathrm{C}, 10 \mathrm{~min}\right)$ to obtain the supernatant. The contents of MMP-1, MMP-3, and procollagen I were determined according to the manufacturer's recommended protocol. The absorbance of the supernatant was measured under the condition of $450 \mathrm{~nm}$ wavelength of the microplate reader, and the standard curve was taken to calculate the level of MMP-1, MMP-3, and type I procollagen.

\subsection{Comet Assay}

Cells grown to a suitable density were treated with DAPTMGY at various concentrations for $2 \mathrm{~h}$. After $24 \mathrm{~h}$, the cells digested by trypsin were centrifuged before discarding the supernatant and resuspending the pellet in PBS. Subsequently, a comet assay was conducted according to the method of Lin et al. [54]. The stained nucleus was observed using an inverted fluorescence microscope (Olympus, Tokyo, Japan).

\subsection{Immunocytochemistry}

Treated cells were washed three times with PBS and fixed in $4 \%$ paraformaldehyde phosphate-buffered solution $\left(4{ }^{\circ} \mathrm{C}, 30 \mathrm{~min}\right)$. The cells were permeabilized with $0.2 \%$ Triton X-100 (20 $\mathrm{min}$ ) on ice and blocked with $5 \%$ bovine serum albumin (BSA, $1 \mathrm{~h}$ ) at room temperature, followed by incubation with p53 antibody $\left(1: 500,4{ }^{\circ} \mathrm{C}\right)$ overnight. After washing by PBS, the cells were bathed in goat anti-mouse IgG Dylight 488 (1:500; $2 \mathrm{~h})$ and Actin red $(1: 100,1 \mathrm{~h})$ at room temperature. The nuclei were stained using 4',6-diamidino-2phenylindole (DAPI) and then viewed using an inverted fluorescence microscope (Olympus Opticals, Tokyo, Japan).

\subsection{Molecular Docking}

The structures of MMP-1 (966c.pdb) and MMP-3 (2JT6.pdb) were obtained from the Protein Data Bank. The docking method and steps were consistent with a previous study [55], and the best 3D docking pose was visualized. 


\subsection{Statistical Analysis}

GraphPad Prism 8 (GraphPad Software, San Diego, CA, USA), CAPS (Version 1.2.3 beta1, Krzysztof Konca, url: CaspLab.com, accessed 1 February 2021), and Image J (Version $1.46 \mathrm{r}, \mathrm{NIH}$ ) were used for data analyses. One-way analysis of variance (ANOV A) was applied, and the differences between two groups were analyzed using Dunnett's multiple comparison test. All experiment data were recorded in triplicate and expressed as the mean \pm standard deviation; significance was assessed as ${ }^{*} p<0.05,{ }^{* *} p<0.01$, and $* * * 0<0.001$.

\section{Conclusions}

In conclusion, we identified the amino-acid sequence of DAPTMGY and examined its anti-photoaging properties, as well as its underlying mechanism of inhibitory action, through in vitro assays and molecular docking analysis. Treatment with DAPTMGY attenuated UV-induced photoaging in HaCaT cells through suppression of ROS generation, apoptosis signaling transduction, and MMP expression (Figure 9). Thus, this study identified DAPTMGY as a novel peptide from marine microalgae, I. zhanjiangensis with potential to inhibit photoaging.

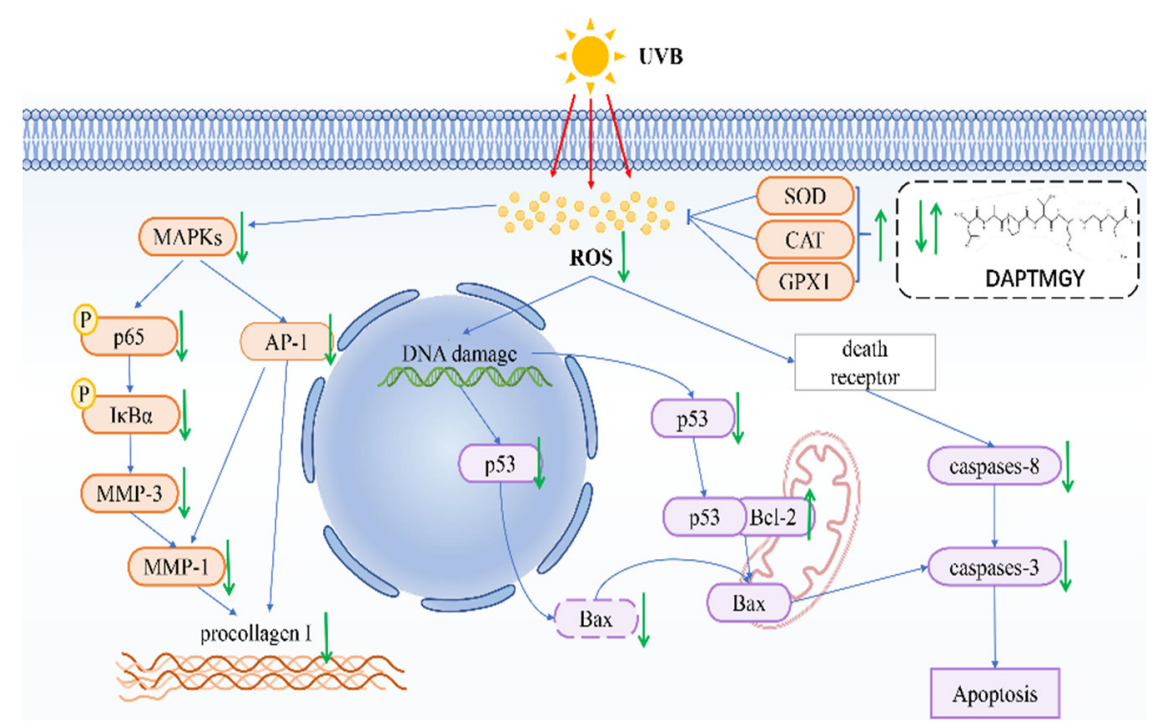

Figure 9. Mechanism summary of DAPTMGY against UVB-irradiated HaCaT cells oxidative and apoptosis.

Author Contributions: Z.Z. and Z.X. performed the experiment and wrote the manuscript; Z.-J.Q. conceived the research and revised the manuscripts; Y.-L.H., Y.T. and L.L. analyzed the data; C.Z., H.L. and P.H. contributed materials and analysis tools. All authors have read and agreed to the published version of the manuscript.

Funding: The research was funded by the 2020 Shenzhen International Scientific and Technological Cooperation R\&D Project (GJHZ20190823111601682) and Guangdong Basic and Applied Basic Research Foundation (2020A1515011075). The supported by the Development Project about Marine Economy Demonstration of Zhanjiang City (XM-202008-01B1) and Southern Marine Science and Engineering Guangdong Laboratory (Zhanjiang, ZJW-2019-07).

Institutional Review Board Statement: Not applicable.

Informed Consent Statement: Not applicable.

Data Availability Statement: All data is contained within this article.

Conflicts of Interest: The authors declare no conflict of interest. 


\section{References}

1. Jurkiewicz, B.A.; Buettner, G.R. Ultraviolet light-induced free radical formation in skin: An electron paramagnetic resonance study. Photochem. Photobiol. 1994, 59, 1-4. [CrossRef] [PubMed]

2. Zastrow, L.; Doucet, O.; Ferrero, L.; Groth, N.; Klein, F.; Kockott, D.; Lademann, J. Free Radical Threshold Value: A New Universal Body Constant. Ski. Pharmacol. Physiol. 2015, 28, 264-268. [CrossRef]

3. Parrado, C.; Mascaraque, M.; Gilaberte, Y.; Juarranz, A.; Gonzalez, S. Fernblock (Polypodium leucotomos Extract): Molecular Mechanisms and Pleiotropic Effects in Light-Related Skin Conditions, Photoaging and Skin Cancers, a Review. Int. J. Mol. Sci. 2016, 17, 1026. [CrossRef] [PubMed]

4. Kammeyer, A.; Luiten, R.M. Oxidation events and skin aging. Ageing Res. Rev. 2015, 21, 16-29. [CrossRef]

5. Wang, L.; Oh, J.Y.; Kim, Y.S.; Lee, H.G.; Jeon, Y.J. Anti-Photoaging and Anti-Melanogenesis Effects of Fucoidan Isolated from Hizikia fusiforme and Its Underlying Mechanisms. Mar. Drugs 2020, 18, 427. [CrossRef]

6. Qu, D.; Venzon, D.; Murray, M.; Depauw, M. Noninvasive measurement of advanced glycation end-products in the facial skin: New data for skin aging studies. J. Cosmet. Sci. 2017, 68, 195-204.

7. Zhang, X.; Feng, C.; Wang, S.; Wang, Y.; Fu, Z.; Zhang, Y.; Sun, H.; Xie, C.; Fu, Y.; Tao, J.; et al. A novel amphibian-derived peptide alleviated ultraviolet B-induced photodamage in mice. Biomed. Pharmacother. 2021, 136, 111258. [CrossRef] [PubMed]

8. Sharma, S.D.; Katiyar, S.K. Dietary Grape Seed Proanthocyanidins Inhibit UVB-Induced Cyclooxygenase-2 Expression and Other Inflammatory Mediators in UVB-Exposed Skin and Skin Tumors of SKH-1 Hairless Mice. Pharm. Res. 2010, 27, $1092-1102$. [CrossRef]

9. Sathasivam, R.; Radhakrishnan, R.; Hashem, A.; Abd Allah, E.F. Microalgae metabolites: A rich source for food and medicine. Saudi J. Biol. Sci. 2019, 26, 709-722. [CrossRef] [PubMed]

10. Yang, X.; Wu, Y.; Yan, J.; Song, H.; Fan, J.; Li, Y. Trends of microalgal biotechnology: A view from bibliometrics. Sheng Wu Gong Cheng Xue Bao Chin. J. Biotechnol. 2015, 31, 1415-1436.

11. Vaz, B.D.; Moreira, J.B.; de Morais, M.G.; Costa, J.A.V. Microalgae as a new source of bioactive compounds in food supplements. Curr. Opin. Food Sci. 2016, 7, 73-77. [CrossRef]

12. Kusmayadi, A.; Leong, Y.K.; Yen, H.W.; Huang, C.Y.; Chang, J.S. Microalgae as sustainable food and feed sources for animals and humans-Biotechnological and environmental aspects. Chemosphere 2021, 271, 129800. [CrossRef]

13. Zhu, J.; Rong, J.; Zong, B. Factors in mass cultivation of microalgae for biodiesel. Chin. J. Catal. 2013, 34, 80-100. [CrossRef]

14. Wang, Q.; Gong, Y.; Liu, S.; Wang, D.; Liu, R.; Zhou, X.; Nghiem, L.D.; Zhao, Y. Free Ammonia Pretreatment To Improve Bio-hydrogen Production from Anaerobic Dark Fermentation of Microalgae. Acs Sustain. Chem. Eng. 2019, 7, $1642-1647$. [CrossRef]

15. Aguilar-Toala, J.E.; Hernandez-Mendoza, A.; Gonzalez-Cordova, A.F.; Vallejo-Cordoba, B.; Liceaga, A.M. Potential role of natural bioactive peptides for development of cosmeceutical skin products. Peptides 2019, 122, 170170. [CrossRef] [PubMed]

16. Ko, S.-C.; Kim, D.; Jeon, Y.-J. Protective effect of a novel antioxidative peptide purified from a marine Chlorella ellipsoidea protein against free radical-induced oxidative stress. Food Chem. Toxicol. 2012, 50, 2294-2302. [CrossRef] [PubMed]

17. Guzmán, F.; Wong, G.; Román, T.; Cárdenas, C.; Alvárez, C.; Schmitt, P.; Albericio, F.; Rojas, V. Identification of Antimicrobial Peptides from the Microalgae Tetraselmis suecica (Kylin) Butcher and Bactericidal Activity Improvement. Mar. Drugs 2019, 17, 453. [CrossRef] [PubMed]

18. Sheih, I.C.; Wu, T.-K.; Fang, T.J. Antioxidant properties of a new antioxidative peptide from algae protein waste hydrolysate in different oxidation systems. Bioresour. Technol. 2009, 100, 3419-3425. [CrossRef]

19. Chen, M.F.; Zhang, Y.Y.; He, M.D.; Li, C.Y.; Zhou, C.X.; Hong, P.Z.; Qian, Z.J. Antioxidant Peptide Purified from Enzymatic Hydrolysates of Isochrysis Zhanjiangensis and Its Protective Effect against Ethanol Induced Oxidative Stress of HepG2 Cells. Biotechnol. Bioprocess Eng. 2019, 24, 308-317. [CrossRef]

20. Chen, J.; Tan, L.; Li, C.; Zhou, C.; Hong, P.; Sun, S.; Qian, Z.-J. Mechanism Analysis of a Novel Angiotensin-I-Converting Enzyme Inhibitory Peptide from Isochrysis zhanjiangensis Microalgae for Suppressing Vascular Injury in Human Umbilical Vein Endothelial Cells. J. Agric. Food Chem. 2020, 68, 4411-4423. [CrossRef]

21. Selimovic, D.; Ahmad, M.; El-Khattouti, A.; Hannig, M.; Haikel, Y.; Hassan, M. Apoptosis-related protein-2 triggers melanoma cell death by a mechanism including both endoplasmic reticulum stress and mitochondrial dysregulation. Carcinogenesis 2011, 32, 1268-1278. [CrossRef] [PubMed]

22. Soares de Castro, R.J.; Sato, H.H. Biologically active peptides: Processes for their generation, purification and identification and applications as natural additives in the food and pharmaceutical industries. Food Res. Int. 2015, 74, 185-198. [CrossRef] [PubMed]

23. Mark, R.; Johannes, B.; Maria, S.; Andrea, T.; Klaus, R. Oxidative Stress in Aging Human Skin. Biomolecules $2015,5,545-589$.

24. Teixeira, T.R.; Rangel, K.C.; Tavares, R.; Kawakami, C.M.; Debonsi, H.M. In Vitro Evaluation of the Photoprotective Potential of Quinolinic Alkaloids Isolated from the Antarctic Marine Fungus Penicillium echinulatum for Topical Use. Mar. Biotechnol. 2021, 23, 357-372. [CrossRef] [PubMed]

25. Lee, C.-Y.; Choy, C.-S.; Lai, Y.-C.; Chang, C.-C.; Teng, N.-C.; Huang, W.-T.; Lin, C.-T.; Huang, Y.-K. A Cross-Sectional Study of Endogenous Antioxidants and Patterns of Dental Visits of Periodontitis Patients. Int. J. Environ. Res. Public Health 2019, 16, 180. [CrossRef]

26. Naqash, S.Y.; Nazeer, R.A. In Vitro Antioxidant and Antiproliferative Activities of Bioactive Peptide Isolated from Nemipterus Japonicus BackbonE. Int. J. Food Prop. 2012, 15, 1200-1211. [CrossRef] 
27. Saidi, S.; Saoudi, M.; Ben Amar, R. Valorisation of tuna processing waste biomass: Isolation, purification and characterisation of four novel antioxidant peptides from tuna by-product hydrolysate. Environ. Sci. Pollut. Res. 2018, 25, 17383-17392. [CrossRef]

28. Chen, N.; Yang, H.; Sun, Y.; Niu, J.; Liu, S. Purification and identification of antioxidant peptides from walnut (Juglans regia L.) protein hydrolysates. Peptides 2012, 38, 344-349. [CrossRef]

29. Ogawa, T.; Araki, M.; Miyamae, T.; Okayama, T.; Hagiwara, M.; Sakurada, S.; Morikawa, T. Synthesis and Antinociceptive activity of orally active opioid peptides: Improvement of oral bioavailability by esterification. Chem. Pharm. Bull. 2003, 51, 759-771. [CrossRef]

30. Caylak, E.; Aytekin, M.; Halifeoglu, I. Antioxidant effects of methionine, alpha-lipoic acid, N-acetylcysteine and homocysteine on lead-induced oxidative stress to erythrocytes in rats. Exp. Toxicol. Pathol. 2008, 60, 289-294. [CrossRef]

31. Bin, P.; Huang, R.; Zhou, X. Oxidation Resistance of the Sulfur Amino Acids: Methionine and Cysteine. Biomed Res. Int. 2017, 2017, 1-6. [CrossRef] [PubMed]

32. Kim, E.-K.; Tang, Y.; Kim, Y.-S.; Hwang, J.-W.; Choi, E.-J.; Lee, J.-H.; Lee, S.-H.; Jeon, Y.-J.; Park, P.-J. First Evidence that Ecklonia cava-Derived Dieckol Attenuates MCF-7 Human Breast Carcinoma Cell Migration. Mar. Drugs 2015, 13, 1785-1797. [CrossRef]

33. Hidayat, A.F.A.; Chan, C.K.; Mohamad, J.; Kadir, H.A. Dioscorea bulbifera induced apoptosis through inhibition of ERK $1 / 2$ and activation of JNK signaling pathways in HCT116 human colorectal carcinoma cells. Biomed. Pharmacother. 2018, 104, 806-816. [CrossRef] [PubMed]

34. Kim, K.C.; Kim, D.; Kim, S.C.; Jung, E.; Park, D.; Hyun, J.W. Empetrum nigrum var. japonicum Extract Suppresses Ultraviolet B-Induced Cell Damage via Absorption of Radiation and Inhibition of Oxidative Stress. Evid.-Based Complementary Altern. Med. 2013, 2013, 983609.

35. Raisova, M.; Hossini, A.M.; Eberle, J.; Riebeling, C.; Wieder, T.; Sturm, I.; Daniel, P.T.; Orfanos, C.E.; Geilen, C.C. The Bax/Bcl-2 ratio determines the susceptibility of human melanoma cells to CD95/Fas-mediated apoptosis. J. Investig. Dermatol. 2001, 117, 333-340. [CrossRef]

36. Pustisek, N.; Situm, M. UV-radiation, apoptosis and skin. Coll. Antropol. 2011, 35 (Suppl. S2), 339-341. [PubMed]

37. Wu, Y.; Xing, D.; Liu, L.; Gao, B. Regulation of Bax activation and apoptotic response to UV irradiation by p53 transcriptiondependent and -independent pathways. Cancer Lett. 2008, 271, 231-239. [CrossRef]

38. Plopper, G.; Sharp, D.; Sikorski, E.F. Lewin's Cells + Online Access, 3rd ed.; Jones \& Bartlett Publishers: Sudbury, MA, USA, 2014.

39. Brittain, T. The Role of Cytochrome C in Apoptosis: Recent Revelations (Chapter); Thom Nova Press: New York, NY, USA, 2014.

40. Lee, C.-H.; Wu, S.-B.; Hong, C.-H.; Yu, H.-S.; Wei, Y.-H. Molecular Mechanisms of UV-Induced Apoptosis and Its Effects on Skin Residential Cells: The Implication in UV-Based Phototherapy. Int. J. Mol. Sci. 2013, 14, 6414-6435. [CrossRef]

41. Choi, S.-Y.; Bin, B.-H.; Kim, W.; Lee, E.; Lee, T.R.; Cho, E.-G. Exposure of human melanocytes to UVB twice and subsequent incubation leads to cellular senescence and senescence-associated pigmentation through the prolonged p53 expression. J. Dermatol. Sci. 2018, 90, 303-312. [CrossRef]

42. Wang, H.; Zhang, M.; Xu, X.; Hou, S.; Liu, Z.; Chen, X.; Zhang, C.; Xu, H.; Wu, L.; Liu, K.; et al. IKKalpha mediates UVB-induced cell apoptosis by regulating p53 pathway activation. Ecotoxicol. Environ. Saf. 2021, 227, 112892. [CrossRef]

43. Aufiero, B.M.; Talwar, H.; Young, C.; Krishnan, M.; Hatfield, J.S.; Lee, H.K.; Wong, H.K.; Hamzavi, I.; Murakawa, G.J. Narrow-band UVB induces apoptosis in human keratinocytes. J. Photochem. Photobiol. B-Biol. 2006, 82, 132-139. [CrossRef] [PubMed]

44. Sun, Y.; Wang, P.; Li, H.; Dai, J. BMAL1 and CLOCK proteins in regulating UVB-induced apoptosis and DNA damage responses in human keratinocytes. J. Cell. Physiol. 2018, 233, 9563-9574. [CrossRef] [PubMed]

45. Im, A.R.; Kim, Y.-M.; Chin, Y.-W.; Chae, S. Protective effects of compounds from Garcinia mangostana L. (mangosteen) against UVB damage in HaCaT cells and hairless mice. Int. J. Mol. Med. 2017, 40, 1941-1949. [CrossRef]

46. Xiao, Z.; Liang, P.; Chen, J.; Chen, M.-F.; Gong, F.; Li, C.; Zhou, C.; Hong, P.; Yang, P.; Qian, Z.-J. A Peptide YGDEY from Tilapia Gelatin Hydrolysates Inhibits UVB-mediated Skin Photoaging by Regulating MMP-1 and MMP-9 Expression in HaCaT Cells. Photochem. Photobiol. 2019, 95, 1424-1432. [CrossRef]

47. Lalita, S.; Hwan, L.T.; Mustatab, W.H.; So-Hyeon, B.; Yeou, K.S. Resveratrol-Enriched Rice Attenuates UVB-ROS-Induced Skin Aging via Downregulation of Inflammatory Cascades. Oxidative Med. Cell. Longev. 2017, 2017, 8379539.

48. Pavida, P.; Jitlada, M.; Ornicha, P.; Mayumi, K.; Mamitaro, O. Role of Matrix Metalloproteinases in Photoaging and Photocarcinogenesis. Int. J. Mol. Sci. 2016, 17, 868.

49. Jalkute, C.B.; Barage, S.H.; Dhanavade, M.J.; Sonawane, K.D. Molecular Dynamics Simulation and Molecular Docking Studies of Angiotensin Converting Enzyme with Inhibitor Lisinopril and Amyloid Beta Peptide. Protein J. 2013, 32, 356-364. [CrossRef] [PubMed]

50. Tseng, G.-N.; Sonawane, K.D.; Korolkova, Y.V.; Zhang, M.; Liu, J.; Grishin, E.V.; Guy, H.R. Probing the outer mouth structure of the hERG channel with peptide toxin footprinting and molecular modeling. Biophys. J. 2007, 92, 3524-3540. [CrossRef] [PubMed]

51. Wongrattanakamon, P.; Nimmanpipug, P.; Sirithunyalug, B.; Chaiyana, W.; Jiranusornkul, S. Molecular modeling of non-covalent binding of Ligustrum lucidum secoiridoid glucosides to AP-1/matrix metalloproteinase pathway components. J. Bioenerg. Biomembr. 2018, 50, 315-327. [CrossRef]

52. Ramaniah, L.M.; Kamal, C.; Kshirsagar, R.J.; Chakrabarti, A.; Banerjee, A. How universal are hydrogen bond correlations? A density functional study of intramolecular hydrogen bonding in low-energy conformers of alpha-amino acids. Mol. Phys. 2013, 111, 3067-3076. [CrossRef] 
53. Nishio, M.; Umezawa, Y.; Fantini, J.; Weiss, M.S.; Chakrabarti, P. CH-pi hydrogen bonds in biological macromolecules. Phys. Chem. Chem. Phys. 2014, 16, 12648-12683. [CrossRef] [PubMed]

54. Lin, L.; Yang, S.; Xiao, Z.; Hong, P.; Sun, S.; Zhou, C.; Qian, Z.-J. The Inhibition Effect of the Seaweed Polyphenol, 7-Phloro-Eckol from Ecklonia Cava on Alcohol-Induced Oxidative Stress in HepG2/CYP2E1 Cells. Mar. Drugs 2021, 19, 158. [CrossRef] [PubMed]

55. Xiao, Z.; Yang, S.; Chen, J.; Li, C.; Zhou, C.; Hong, P.; Sun, S.; Qian, Z.-J. Trehalose against UVB-induced skin photoaging by suppressing MMP expression and enhancing procollagen I synthesis in HaCaT cells. J. Funct. Food 2020, 74, 104198. [CrossRef] 